\title{
$\alpha$-Tocopheryl succinate potentiates the paclitaxel-induced apoptosis through enforced caspase 8 activation in human H460 lung cancer cells
}

\author{
Soo-Jeong Lim ${ }^{1,4 *}$, Moon Kyung Choi ${ }^{2 *}$, \\ Min Jung Kim ${ }^{1}$ and Joo Kyoung $\mathrm{Kim}^{3}$ \\ ${ }^{1}$ Department of Bioscience and Biotechnology \\ Sejong University \\ Seoul 143-747, Korea \\ ${ }^{2}$ Research Institute \\ National Cancer Center \\ Goyang 410-769, Korea \\ ${ }^{3}$ Seoul Medical Science Institute \\ Seoul 140-809, Korea \\ ${ }^{4}$ Corresponding author: Tel, 82-2-3408-3767; \\ Fax, 82-2-3408-3334; E-mail, sjlim@ sejong.ac.kr \\ *These authors contributed equally to this work. \\ DOI 10.3858/emm.2009.41.10.080
}

Accepted 8 June 2009

Abbreviations: AP-1, activator protein-1; Cox, cyclooxygenase; NSCLC, nonsmall cell lung cancer; PARP, poly(ADP-ribose) polymerase; ROS, reactive oxygen species; TOS, $\alpha$-tocopheryl succinate

\begin{abstract}
Paclitaxel is one of the chemotheraputic drugs widely used for the treatment of nonsmall cell lung cancer (NSCLC) patients. Here, we tested the ability of $\alpha$-tocopheryl succinate (TOS), another promising anticancer agent, to enhance the paclitaxel response in NSCLC cells. We found that sub-apoptotic doses of TOS greatly enhanced paclitaxel-induced growth suppression and apoptosis in the human H460 NSCLC cell lines. Our data revealed that this was accounted for primarily by an augmented cleavage of poly(ADP-ribose) polymerase (PARP) and enhanced activation of caspase-8. Pretreatment with z-VAD-FMK (a pan-caspase inhibitor) or z-IETD-FMK (a caspase-8 inhibitor) blocked TOS/paclitaxel cotreatment-induced PARP cleavage and apoptosis, suggesting that TOS potentiates the paclitaxel-induced apoptosis through enforced caspase 8 activation in $\mathrm{H} 460$ cells. Furthermore, the growth suppression effect of TOS/paclitaxel combination on human H460, A549 and H358 NSCLC cell lines were synergistic. Our observations indicate that combination of paclitaxel and TOS may offer a novel therapeutic strategy for improving paclitaxel drug effi-
\end{abstract}

cacy in NSCLC patient therapy as well as for potentially lowering the toxic side effects of paclitaxel through reduced drug dosage.

Keywords: apoptosis; carcinoma, non-small-cell lung; caspase 8; paclitaxel; $\alpha$-tocopherol

\section{Introduction}

$\alpha$-Tocopheryl succinate (TOS), which is obtained by the esterification of $\alpha$-tocopherol is a more stable powder form of $\alpha$-tocopherol, since the succinate group protects the hydroxyl group of the chromanol ring from oxidation. Despite their similar chemical structures, TOS differs in activity from $\alpha$-tocopherol. For example, TOS is redox-insensitive prior to being cleaved to $\alpha$-tocopherol by intracellular esterases. In contrast to $\alpha$-tocopherol, TOS induces cytotoxic responses in a wide range of cancer cells while sparing normal cells (Weber et al., 2002; Kang et al., 2004). The antitumor effect of TOS appears to be mediated primarily through the induction of apoptosis. TOS has been shown to induce apoptosis in tumor cell lines via multiple pathways. For example, TOS was observed to induce apoptosis in cancer cells by transcriptional activation of activator protein-1 (AP-1)-controlled genes. In other cell lines, the apoptotic activity of TOS was linked to its blockade of cell cycle progression by inhibiting the transcriptional activity of E2F, or by enhancing the expression of $\mathrm{p} 21^{\text {waf1/cip } 1}$, a cell cycle checkpoint protein (Turley et al., 1997). TOS has also been shown to induce apoptosis by activating Fas signaling pathways (Israel et al., 2000). Recently, the proapoptotic activity of TOS has been linked to its ability to induce the accumulation of reactive oxygen species (Kang et al., 2004; Dong et al., 2008), leading to mitochondrial destabilization (Neuzil et al., 2007). TOS-induced apoptosis appears to be mediated by caspase activation in majority of cancer cell lines, although the contribution of caspase 9 or caspase 8 differs depending on the cellular context (Swettenham et al., 2005).

Recently, considerable attention have been given to combination treatment with reduced doses of two or more different anticancer agents, since combination treatment may enhance the therapeutic efficacy of each agent alone, and/or enable 
the use of lower doses of each agent. With this regards, in addition to induction of apoptosis at higher doses, lower doses of TOS acts synergistically with anticancer agents, including selenium, exisulind and SC-560 a selective Cox-1 inhibitor (Lee et al., 2006b; Lim et al., 2007; Reagan-Shaw et al., 2008) to induce apoptosis. The mechanisms supporting the synergistic effects observed in combination treatments remain largely undefined, but involve enhanced apoptosis through enforced caspase activation. These earlier studies suggest a possibility that TOS may be a clinically useful adjuvant in cancer treatment since antitumor effects of chemotherapeutic drugs are mediated at least partly through caspase-mediated apoptosis induction.

Lung cancer is one of leading cause of cancer-related death worldwide. Majority of lung cancer patients are diagnosed with already metastasized or advanced diseases, thus being refractory to current treatment modalities, warranting the needs for developing new preventive or therapeutic drugs. In particular, nonsmall cell lung cancer (NSCLC) is a cancer with poor prognosis despite recent progress made in early diagnosis and treatment. Chemotherapy is an established treatment for advanced NSCLC but still show poor response rates in NSCLC patients (Ihde and Minna, 1991).

Paclitaxel is one of the chemotheraputic drugs widely used for the treatment of NSCLC. This drug binds and stabilize microtubules, and interferes with the dynamic changes that occur during the formation of the mitotic spindles, thereby arresting the cells at the $\mathrm{G}_{2} / \mathrm{M}$ phase (Honore et al., 2005). Paclitaxel also has the ability to induce apoptosis and its cell killing effects are mediated, at least partly, by inducing apoptosis (Wang et al., 2000). Although there are numerous reports about the mechanism underlying apoptosis induced by paclitaxel, how this microtubule polymerizing agent triggers apoptosis remains incompletely understood. Apoptotic cell death caused by paclitaxel often involves various caspase activation (von Haefen et al., 2003; Park et al., 2004). In NSCLC cells in vitro, paclitaxel treatment caused caspase-8- and caspase-3-dependent apoptosis and the apoptosis induction was correlated with the antitumor effect of paclitaxel (Ferreira et al., 2000).

Despite of its potent anticancer activity, the effectiveness of paclitaxel chemotherapy is often limited because of dose-limiting side effects (Zanetta et al., 2000). A major challenge to improving their chemotherapeutic index is by combined treatments that cooperatively or synergistically enhance apoptosis. We herein examined whether TOS and paclitaxel could act synergistically to induce enhanced growth suppression and apoptosis in human H460 NSCLC cells. Our data herein demonstrate that paclitaxell cotreatment with a subapoptotic dose of TOS greatly enhances paclitaxel-induced apoptosis in $\mathrm{H} 460$ cells, at least partially through enforced caspase- 8 activation.
A

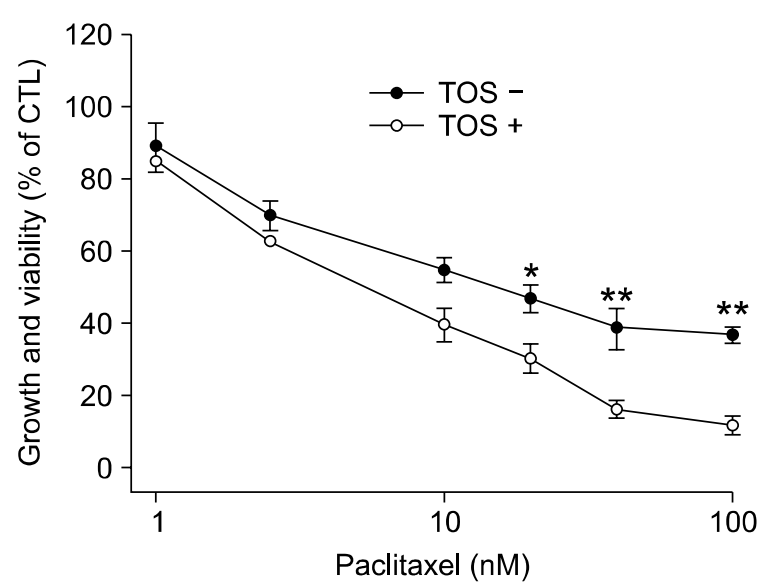

B

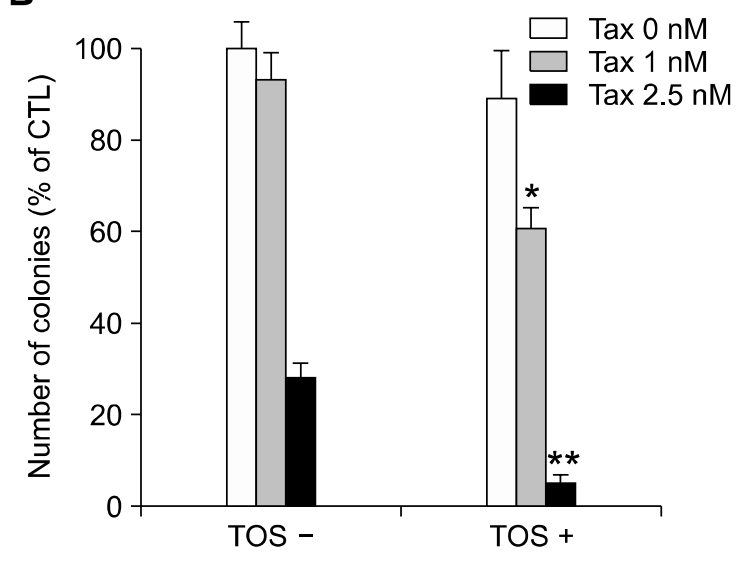

Figure 1. TOS augmented paclitaxel (TAX)-induced growth suppression in H460 cells. (A) Cells were seeded at a density of $2.5 \times 10^{3} /$ well in $96-$ well plates and, starting $24 \mathrm{~h}$ later, were treated with increasing doses of paclitaxel in the presence or absence of TOS $(25 \mu \mathrm{M})$. At $48 \mathrm{~h}$ post-incubation, the growth and viability of cells were determined by using MTT. Results are expressed as percentage growth (mean \pm S.D. of triplicate wells) relative to DMSO-treated cells. (B) Effect of combination treatment on $\mathrm{H} 460$ colony formation. Cells were plated at 500 cells per dish. The medium covering the cells was replaced every three days at the Taxol concentrations indicated on the figure with or without $2.5 \mu \mathrm{M}$ TOS. Colony numbers were counted after 10 days treatment following crystal violet staining. The number of colonies in the dish treated with vehicle alone was used as an index for a $100 \%$ survival rate (control) and this value was used to obtain the percentage survival rates for other dishes. Data are mean \pm SD of three independent experiments. Significant differences are indicated by asterisks: ${ }^{*} P<0.05$ and ${ }^{* *} P<0.005$, compared with cells treated with paclitaxel alone. 


\section{Results}

\section{TOS augmented paclitaxel effect on the growth and colony formation of $\mathrm{H} 460$ cells}

To examine the effect of TOS on paclitaxel-induced growth inhibition, we treated human $\mathrm{H} 460$ lung cancer cells with increasing doses of paclitaxel in the presence or absence of TOS. In the absence of TOS, 10 and $100 \mathrm{nM}$ paclitaxel inhibited the growth of $\mathrm{H} 460$ cells by 45.1 and $63.3 \%$, whereas same doses of paclitaxel inhibited the growth of cells by 60.5 and $89.6 \%$. (Figure 1A). Incubation with $25 \mu \mathrm{M}$ TOS alone showed only a slight inhibitory effect ( $7.5 \%$, data not shown) on the $\mathrm{H} 460$ cell growth.

We performed colony formation assay to evaluate the combination effect by TOS and paclitaxel after long-term treatment. TOS combination increased the paclitaxel-induced inhibition of colony formation in $\mathrm{H} 460$ cells by 5.7 - and 1.3 fold

A

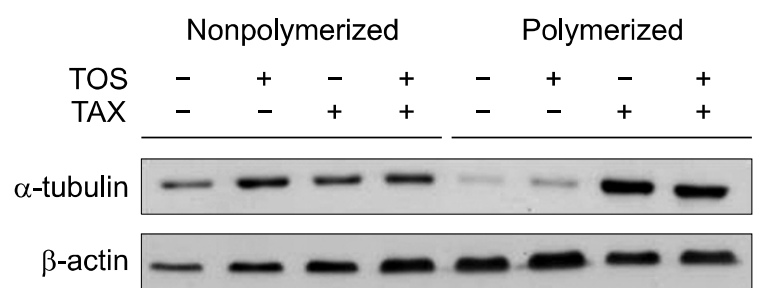

B

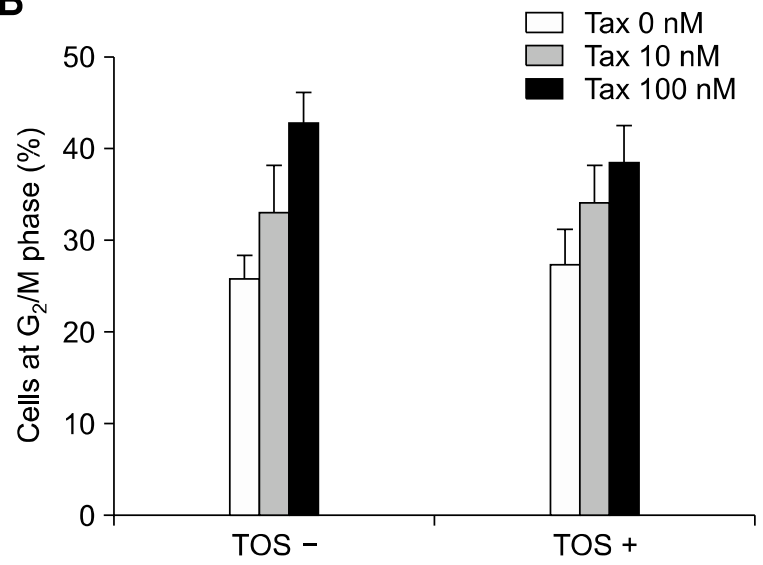

Figure 2. Augmentation by TOS of paclitaxel (TAX)-induced growth inhibition is independent of tubulin polymerization and cell accumulation at $\mathrm{G}_{2} / \mathrm{M}$ phase. (A) $\mathrm{H} 460$ cells were treated with $100 \mathrm{nM}$ paclitaxel in the presence or absence of $25 \mu \mathrm{M}$ TOS for $36 \mathrm{~h}$. Polymerized (cytoskeleton) and non-polymerized (cytosol) tubulin were isolated as described under experimental procedures and resolved on a gel and blotted against anti- $\beta$-tubulin and anti- $\beta$-actin. (B) Accumulation of cells at $G_{2} / M$ phase induced by taxol with or without $25 \mu \mathrm{M}$ TOS co-treatment. Values represent percentages of accumulated cells in the $\mathrm{G}_{2} / \mathrm{M}$ phase and are from three independent experiments compared with paclitaxel alone (Figure 1B). These data collectively indicate that TOS enhanced paclitaxel effect on the growth and colony formation of $\mathrm{H} 460$ cells.

\section{TOS did not affect paclitaxel-induced tubulin polymerization and $\mathrm{G}_{2} / \mathrm{M}$ arrest}

Because the anticancer effect of paclitaxel is known to be initiated by binding to and stabilizing microtubules, we sought to investigate whether TOS combination directly affect paclitaxel-induced tubulin polymerization. The soluble, nonpolymerized tubulin was separated from insoluble, polymerized tubulin and analyzed by immunoblotting using anti-tubulin antibodies. Paclitaxel at $100 \mathrm{nM}$ dose induced polymerization whereas TOS had no effect. The combination of paclitaxel with TOS did not enhance the paclitaxel effect on tubulin polymerization (Figure 2A).

Stabilization of microtubules interferes with the dynamic changes that occur during the formation of the mitotic spindles, thereby arresting the cells at the mitotic phase. When we analyzed the percentage of cells accumulated at $G_{2} / M$ phase after $36 \mathrm{~h}$ paclitaxel treatment, we found that 10 and $100 \mathrm{nM}$ paclitaxel increased the percentage of $\mathrm{H} 460$ cells accumulated in the $G_{2} / M$ phase in a dose-dependent manner. TOS alone slightly increased the percentage of cells in the $G_{2} / M$ phase. However, TOS combination did not change paclitaxel-induced $\mathrm{G}_{2} / \mathrm{M}$ accumulation of cells (Figure 2B). These observations demonstrate that TOS do not affect the paclitaxel effect at the level of tubulin polymerization and mitototic arrest to induce growth suppression.

\section{TOS augmented paclitaxel-induced apoptosis}

We then investigated whether the observed augmenting effect of TOS on paclitaxel-induced growth suppression was associated with potentiation of paclitaxel-induced apoptosis. ELISA-based measurements of histone-associated DNA fragments revealed that $100 \mathrm{nM}$ paclitaxel alone increased DNA fragmentation by 4.1 -fold whereas combination treatment with TOS did by 10.2-fold (Figure $3 A)$. The increase in the apoptosis induced by 100 nM paclitaxel plus TOS combination was even much higher compared with that by $300 \mathrm{nM}$ paclitaxel alone (10.2 vs 4.8 -fold). In addition, we observed an increase in apoptosis-associated morphological changes, including cell shrinkage and chromatin condensation, in cells treated with both TOS and paclitaxel versus cells treated with paclitaxel alone (data not shown). These results 
A

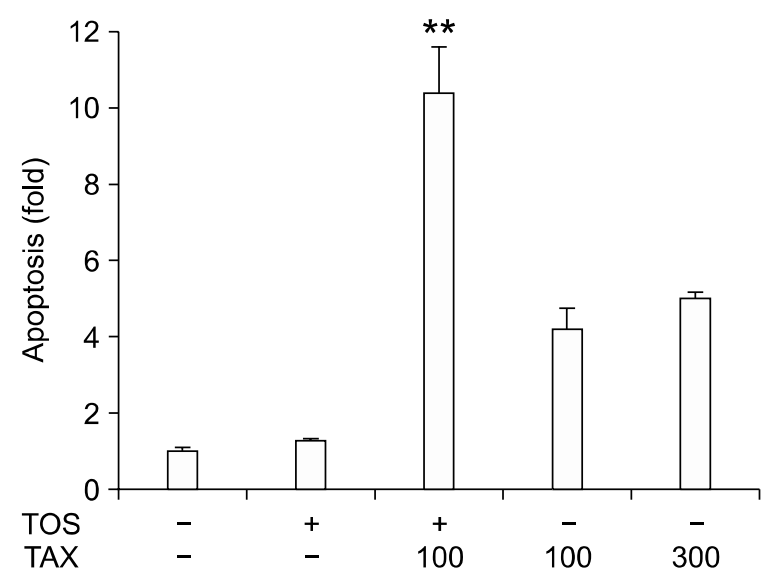

B
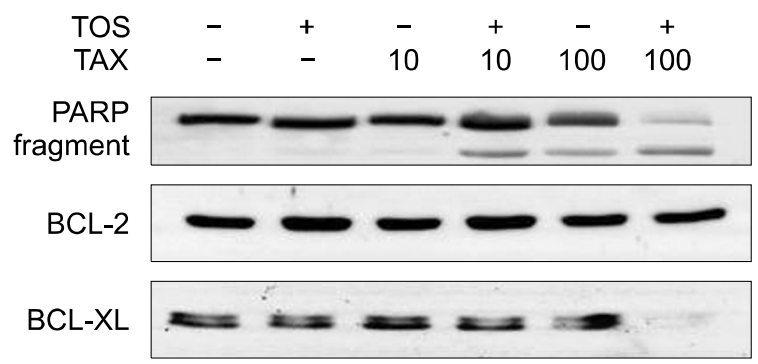

$\beta$-actin

Figure 3. Augmentation by TOS of paclitaxel (TAX)-induced apoptosis. (A) Exponentially growing $\mathrm{H} 460$ cells were treated with the indicated doses of paclitaxel in the absence or presence of TOS $(25 \mu \mathrm{M})$ for $42 \mathrm{~h}$. Apoptosis was quantified by an ELISA that specifically detected histone-associated DNA. Bar represents the net absorbances at the suggested wavelengths ( $A_{405} \mathrm{~nm}$ minus $A_{490} \mathrm{~nm}$ ) (mean $\pm S D$ of four experiments performed in triplicate). Significant differences are indicated by asterisks $:{ }^{* *} P<0.005$ compared with cells treated with paclitaxel alone. (B) Combination treatment induced the cleavage of PARP and decreased the expression of $B C L-X_{L}$ anti-apoptotic protein without affecting that of $\mathrm{BCl}-2$. The expression of proteins was assessed by immunoblotting, in cells harvested after $30 \mathrm{~h}$ treatment. Immunoblotting with an antibody to $\beta$-actin was used to control for equal loading of proteins per lane.

strongly suggest that TOS augments paclitaxel-induced apoptosis in $\mathrm{H} 460$ cancer cells.

Apoptosis was also evaluated by assaying for cleaved PARP, a general marker of apoptosis. Immunoblotting analysis demonstrated the dramatic increase in the levels of cleaved fragments of PARP by TOS combination with paclitaxel: in the absence of TOS, fragmented PARP was detected after treatment with $100 \mathrm{nM}$ paclitaxel, but not with $10 \mathrm{nM}$ paclitaxel. In contrast, in the presence of TOS, PARP fragment was detected already by $10 \mathrm{nM}$ paclitaxel treatment (Figure 3B). TOS alone did not cause PARP fragmentation. Furthermore, when the expression of $\mathrm{Bcl}-2$ family of apoptosis regulators was assayed by immoblotting analysis, we found that the expression of $\mathrm{Bcl}-\mathrm{XL}$ antiapoptotic protein, but not that of $\mathrm{Bcl}-2$ antiapoptotic protein, was decreased by TOS combination (Figure 3B). These data suggest that TOS combination affected the expression profiles of some apoptosis-related proteins.

\section{TOS augmented paclitaxel-induced apoptosis through enforced caspase 8 activation}

Apoptosis is generally associated with caspase activation (Lee et al., 2006a), and paclitaxel-induced apoptosis has been shown to involve the caspase activation cascade. To determine whether paclitaxel/TOS cotreatment-induced apoptosis was mediated through enforced caspase activation, we assayed the activities of caspase-8 and -9 , two major initiator caspases. The decrease in the expression of procaspase- 8 protein was detected by paclitaxel alone from $100 \mathrm{nM}$ doses but from paclitaxel doses as low as $10 \mathrm{nM}$ by TOS combination (Figure 4A). On the other hand, the expression of procaspase-9 protein was not decreased by paclitaxel treatment regardless of TOS combination (Figure 4A). We next investigated whether paclitaxel/TOS cotreatment induced activation of caspase-3, a major effector caspase. Without TOS combination, the decrease in the expression of procaspase- 3 protein was detected by paclitaxel at $100 \mathrm{nM}$ dose, whereas it was detected by $10 \mathrm{nM}$ paclitaxel plus TOS combination. Concomitantly, the catalytically active form of caspase-3 (p17/p19) was evident in $\mathrm{H} 460$ cells when they were treated with paclitaxel alone at doses as high as $100 \mathrm{nM}$, whereas it was detected in cells treated with paclitaxel at doses as low as $10 \mathrm{nM}$ in combination with TOS (Figure 4A).

Figure 4B shows that the activity of caspase- 8 was increased by paclitaxel and further increased by paclitaxel and TOS combination, in consistent with immunoblotting anlaysis data. The activity of caspase- 9 was not affected by paclitaxel treatment regardless of TOS combination.

We then examined whether pretreatment of cells with z-LEHD-FMK (a caspase-9 inhibitor), z-IETDFMK (a caspase-8 inhibitor) or Z-VAD-FMK (a pan-caspase inhibitor) could inhibit the apoptotic cell death induced by paclitaxel/TOS cotreatment. Our results revealed that pan-caspase inhibition and specific inhibition of caspase-8 greatly blocked cotreatment-induced apoptosis, as shown by signi- 
A

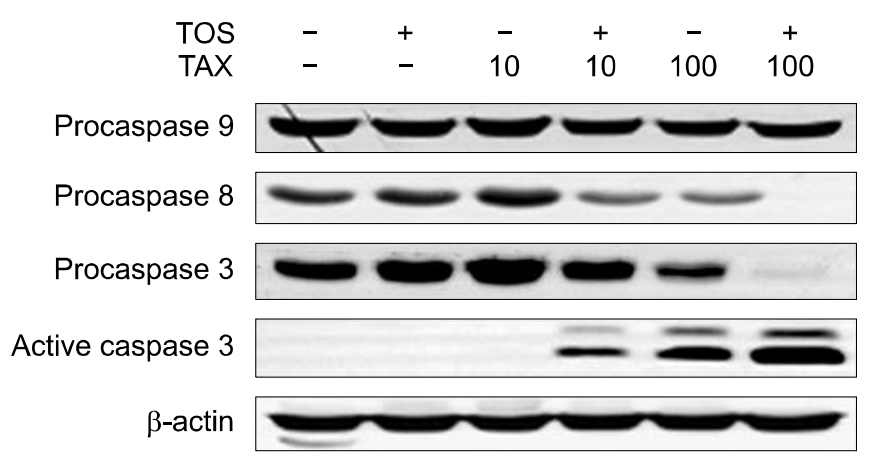

B
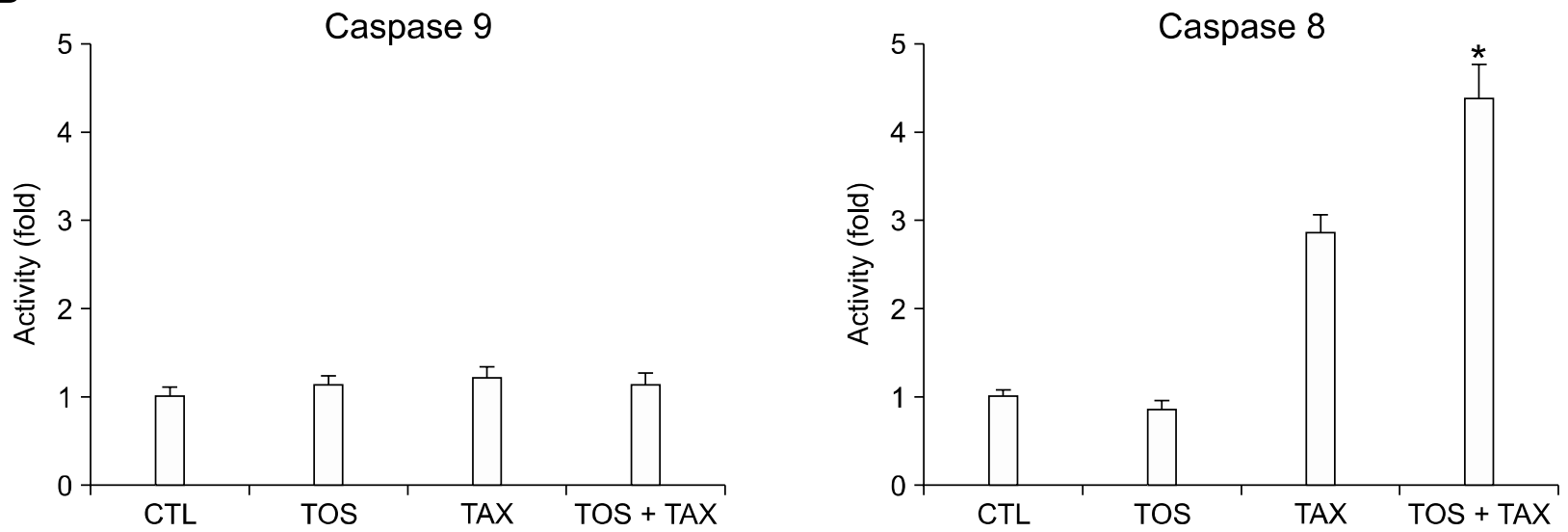

Figure 4. TOS combination potentiated paclitaxel (TAX)-induced caspase 8 activation. (A) Combination treatment induced activation of caspase-8 and -3 but not -9 , in $\mathrm{H} 460$ cells. Expression of active caspase-3 fragment, procaspase- $3,-8$ and -9 were assayed by immunoblotting of cell lysates obtained from cells treated with indicating concentrations of paclitaxel in the presence or absence of $25 \mu \mathrm{M}$ TOS for $30 \mathrm{~h}$. Immunoblotting with an antibody to $\beta$-actin was used to control for equal loading of proteins per lane. (B) Cell lysates obtained after 36-h treatment with $50 \mathrm{nM}$ paclitaxel in the presence or absence of $25 \mu \mathrm{M}$ TOS were incubated with the reaction buffer containing the appropriate caspase fluorogenic substrate. Reactions were proceeded as described in the text, and fluorescence was determined. Bar represents the ratio of the fluorescence in cells treated as indicated and in control (DMSO) cells. Data represent the average of at least three separate experiments. Significant differences are indicated by asterisks: ${ }^{*} P<0.05$, compared with cells treated with paclitaxel alone.

ficant decreases in DNA fragmentation (Figure $5 \mathrm{~A}$ ) and PARP cleavage (Figure 5B). z-LEHD-FMK pretreatment only slightly inhibited the cotreatment-induced DNA fragmentation and PARP cleavage (to much less extent compared with z-IETD-FMK or z-VAD-FMK). In addition, pan-caspase inhibition and specific inhibition of caspase-8, but not that of caspase-9, led to the inhibition of caspase 3 activation (Figure 5B), suggesting that paclitaxel/TOS combination induced activation of caspase-8, an initiator caspase, leading to the subsequent activation of caspase- 3 , an effector caspase. These findings collectively indicate that paclitaxel/TOS cotreatment-induced apoptosis is mediated by and dependent upon caspase- 8 activation in H460 cells. We conclude that TOS cotreatment lowered the paclitaxel dose required to induce caspase 8-activation in $\mathrm{H} 460$ cells.

\section{TOS also augmented paclitaxel response in other lung cancer cell lines}

We sought to examine whether potentiation by TOS on paclitaxel response was also observed in other human NSCLC cells. To statistically evaluate whether the combination of TOS and paclitaxel is synergistic in NSCLC cells, we determined the combination index at two fixed doses of paclitaxel in three NSCLC cell lines. The concentration of TOS for assessing the combination index with paclitaxel was adjusted to a dose only slightly affecting the growth $(<10 \%)$ of corresponding cells by itself. Under these conditions, the combination index was less than 1.0 in all three cell lines, suggesting that TOS and paclitaxel are synergistic (Table 1). This finding thus suggests that TOS synergistically acts with paclitaxel to suppress the growth of human NSCLC cells. 
Table 1. Combination index of NSCLC cell lines. Synergism was assessed by the method of Chou and Talalay using a nonfixed ratio experimental design and the Calcusyn software (Biosoft, Ferguson, MO). Combination index values $<1.0$ indicates synergism.

\begin{tabular}{cccc}
\hline Paclitaxel & \multicolumn{3}{c}{ Combination Index } \\
\cline { 2 - 4 } Dose & $\mathrm{H} 460$ & $\mathrm{~A} 549$ & $\mathrm{H} 358$ \\
\hline $\mathrm{IC}_{50}{ }^{\mathrm{a}}$ & $0.784 \pm 0.067$ & $0.755 \pm 0.082$ & $0.789 \pm 0.068$ \\
$\mathrm{IC}_{70}{ }^{\mathrm{b}}$ & $0.419 \pm 0.064$ & $0.775 \pm 0.049$ & $0.605 \pm 0.102$
\end{tabular}

$\overline{a, b} \mathrm{IC}_{50}$ and $\mathrm{IC}_{70}$ indicates the concentrations inhibiting the cell growth by 50 and $70 \%$, respectively.

\section{Discussion}

Our earlier data showed that TOS, a vitamin E analogue and promising, pharmacologically acceptable anticancer agent, enhanced the exisulind-induced growth suppression in human colorectal cancer cells (Lim et al., 2007). In the present report, we show for the first time that TOS, synergistically enhanced paclitaxel response in human NSCLC cell lines. Our findings suggest that TOS/paclitaxel combination treatment, by improving paclitaxel drug efficacy and lowering its toxic side effects through reduced drug dosage, may provide the basis for new combinatory strategies for the effective treatment of NSCLC that have shown poor response to chemotherapy.

Although paclitaxel has also shown to exhibit its anticancer activity mainly by inducing tubulin polymerization and mitotic arrest, our data show that TOS combination did not affect the extent of tubulin polymerization and $G_{2} / M$ arrest induced by paclitaxel. However, augmentation by TOS of paclitaxel response was correlated with enhanced apoptosis, suggesting that TOS combination affected paclitaxel response mainly at the apoptosis level. Enhanced apoptosis induced by TOS/paclitaxel combination was accompanied by changes in the expression profile of $\mathrm{Bcl}-\mathrm{XL}$ antiapoptotic protein. Overexpression of antiapoptotic proteins including $\mathrm{Bcl}-\mathrm{XL}$ in cancer cells has been recognized as one plausible mechanism of developing resistance to paclitaxel (Lebedeva et al., 2000; Williams et al., 2005), and the inhibition of Bcl-XL by genetic or pharmacological approaches has been shown to sensitize cancer cells to paclitaxel (Shoemaker et al., 2006). With this regards, the significance of $\mathrm{Bcl}-\mathrm{XL}$ downregulation by TOS/paclitaxel combination observed here deserves further speculation.

Since previous studies from our lab and other groups have shown that the accumulation of intracellular reactive oxygen species (ROS) was an early and crucial step for paclitaxel- or TOS-induced apoptotic cell death in human cancer cells

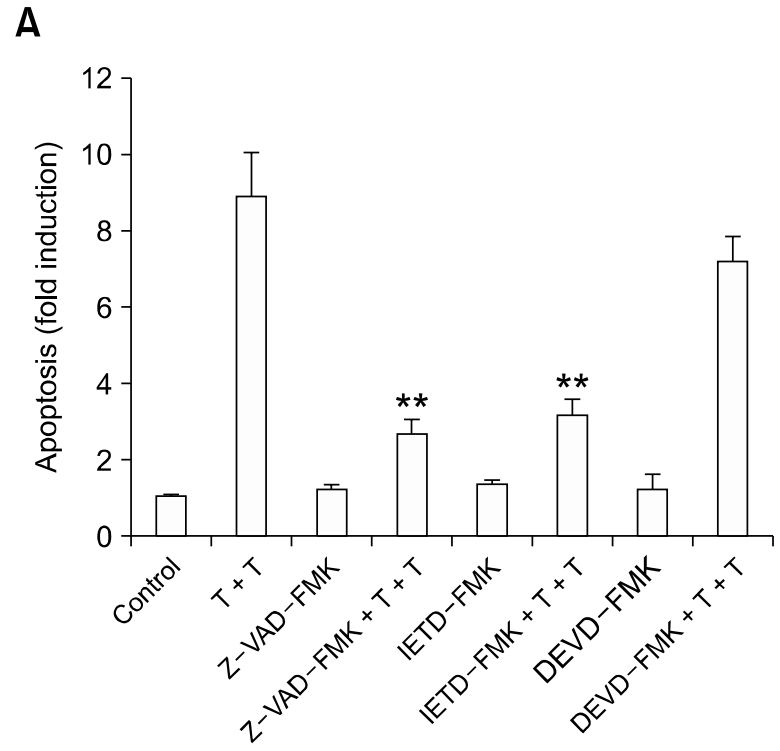

B

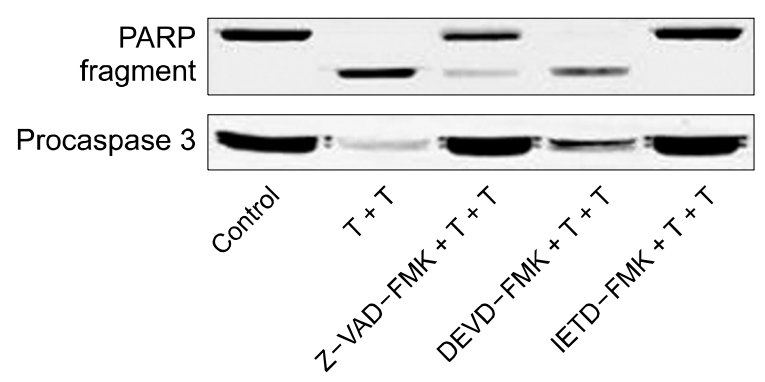

Figure 5. Caspase-8 inhibition blocked the apoptosis induced by paclitaxel and TOS combination. (A) Effect of pretreatment with caspase-9 inhibitor z-LEHD-FMK, caspase-8 inhibitor z-IETD-FMK or the pan-caspase inhibitor Z-VAD-FMK on the apoptosis induced by TOS and paclitaxel combination. After 2-h pretreatment with $25 \mu \mathrm{M}$ of each caspase inhibitor, H460 cells were treated with paclitaxel $(100 \mathrm{nM})$ and TOS (25 $\mu \mathrm{M})$ for $30 \mathrm{~h}$, and subjected to apoptosis ELISA assay. Bar represents the net absorbances at the suggested wavelengths $\left(A_{405} \mathrm{~nm}\right.$ minus $A_{490}$ ${ }_{\mathrm{nm}}$ ) (mean $\pm S D$ of four experiments performed in triplicate). Data represent the average $\pm S D$ of two separate experiments. Significant differences are indicated by asterisks: ${ }^{*} P<0.01$, compared with cells treated with TOS plus taxol. (B) Effect of pretreatment with caspase inhibitors on the PARP cleavage and caspase-3 activation induced by combination treatment with TOS and paclitaxel. After 2-h pretreatment with $25 \mu \mathrm{M}$ of each inhibitor, $\mathrm{H} 460$ cells were treated with paclitaxel (100 nM) and TOS $(25 \mu \mathrm{M})$ for $30 \mathrm{~h}$, and subjected to immunoblot analysis. Two additional studies yielded similar results. Paclitaxel and TOS combination treatement was abbreviated as $\mathrm{T}+\mathrm{T}$ in the Figure.

(Kang et al., 2004; Alexandre et al., 2006), we further examined whether TOS cooperated with paclitaxel in the ROS production to increase apoptosis. However, we found that TOS had no effect on paclitaxel-induced ROS generation and that preincubation of cells with antioxidants did not 
block the TOS/paclitaxel-induced apoptosis (unpublished data), suggesting that that ROS generation does not play a role in the synergistic apoptosis induced by TOS/paclitaxel cotreatment.

Our data indicate that the potentiation by TOS of paclitaxel-induced apoptosis was mediated through enforced activation of caspases, in particular that of caspase-8. In our study, paclitaxel induced the activation of caspase- 8 and -3 but not that of caspase- 9 in H460 cells regardless of TOS combination. This is in consistent with previous data from other groups using $\mathrm{H} 460$ cells (Ferreira et al., 2000). Considering that caspase- 9 is also generally involved in mediating paclitaxel-induced apoptosis in many other cell lines, we cannot exclude a possibility that specific TOS effect on caspase-8 activation may be limited to $\mathrm{H} 460$ cell lines. Future work will be required to address whether TOS also enhances paclitaxel-induced caspase 9 activation by using other cell lines.

Although the activity of TOS has been translated to cancer suppression in a variety of preclinical models (Hahn et al., 2006), the in vivo antitumor activity of TOS have shown to be compromised if orally administrated due to the hydrolysis by esterases in the gastrointestinal tract. Currently, researchers are seeking to develop structural analogues of tocopheryl succinate having more potent anticancer activity after oral administration (Dong et al., 2009). Since our data suggest that TOS holds promising therapeutic potential as an anticancer agent to combine with paclitaxel to improve chemotherapy of NSCLC, it would be of interest to investigate whether TOS or its structural analogue in combination with paclitaxel exert synergistic growth inhibitory effect in vivo.

\section{Methods}

\section{Cell lines and cultures}

The human $\mathrm{H} 460$ and A549 lung cancer cell lines were purchased from the American Type Culture Collection (ATCC, Manassas, VA), and the human H358 cell line was purchased from the Korean Cell Line Bank (Seoul, Korea). Cells were cultured in RPMI 1640 medium supplemented with $10 \%$ heat-inactivated FBS (Hyclone, Logan, UT) and 100 units $/ \mathrm{ml}$ each of penicillin and streptomycin. All cells were grown in incubators in a humid atmosphere of $95 \%$ air $/ 5 \% \mathrm{CO}_{2}$.

\section{Reagents and antibodies}

$\alpha$-tocopheryl succinate (TOS) and MTT were obtained from Sigma (St. Louis, MO). paclitaxel was obtained from Tocris (Tocris Cookson, MO). z-VAD-FMK (pan-caspase inhibitor), z-IETD-FMK (caspase-8 inhibitor) and z-LEHD-FMK (cas- pase-9 inhibitor) were obtained from Enzyme Systems Products (Livemore, CA). Ac-IETD-AFC (caspase- 8 substrate) and Ac-LEHD-AFC (caspase-9 substrate) were purchased from Alexis Biochemicals (Lausen, Switzerland). Antibodies to human poly(ADP-ribose)polymerase (PARP) and $\mathrm{Bcl}-\mathrm{X}$ were purchased from BD Pharmingen (San Diego, CA) and antibodies to active caspase 3 and procaspase- $3,-8$ and -9 were obtained from Cell Signaling Technologies (Beverly, MA). Antibody to $\beta$-tubulin was purchased from Oncogene Research Products (San Diego, $\mathrm{CA})$. Antibodies to Bcl-2 and $\beta$-actin were obtained from Santa Cruz Biotechnology (CA) and Sigma (St. Louis, $\mathrm{MO})$.

All other chemicals were of reagent grade and used without further purification.

\section{Cell viability analysis}

Cells $\left(2.5-5 \times 10^{3} /\right.$ well in $0.1 \mathrm{ml}$ medium) were seeded into 96 -well plates. Starting $24 \mathrm{~h}$ later, cells were treated with various doses of paclitaxel or DMSO vehicle in the presence or absence of $25 \mu \mathrm{M}$ TOS (stock in DMSO at 50 $\mathrm{mM}$ ). At $72 \mathrm{~h}$ postincubation, the growth and viability of cells were determined by using MTT (Sigma). The ability of cells to form formazan crystals by active mitochondrial respiration was determined using a microplate spectrophotometer (Molecular Devices) after dissolving the crystals in DMSO.

\section{Colony formation assay}

500 cells were seeded in $5 \mathrm{~cm}$ diameter dishes and incubated for $16 \mathrm{~h}$ at $37^{\circ} \mathrm{C}$ in an atmosphere containing $5 \%$ $\mathrm{CO}_{2}$. Cells were then treated with increasing concentrations of paclitaxel in the presence or absence of TOS. The medium containing treatments was replaced every three days. After 10 days, surviving cells forming visible colonies (containing $>50$ cells) were counted after staining with crystal violet in $60 \%$ methanol.

\section{Immunoblotting}

At time of harvest, treated cells were scraped from the plates, washed twice with ice-cold PBS, and pelleted at $2,400 \times g$ for $5 \mathrm{~min}$. The cell pellet was then incubated for $15-30 \mathrm{~min}$ on ice in the lysis buffer containing $150 \mathrm{mM} \mathrm{NaCl}$, $10 \mathrm{mM}$ Tris, $0.2 \%$ Triton X-100, 0.3\% NP-40, $0.2 \mathrm{mM}$ $\mathrm{Na}_{3} \mathrm{VO}_{4}$ and protease inhibitors (Roche Diagnostics), $\mathrm{pH}$ 7.4. After centrifugation at $14,000 \mathrm{rpm}$ for $15 \mathrm{~min}$ at $4^{\circ} \mathrm{C}$, the supernatants were collected, and the protein concentration in each was measured by the Bradford method. Aliquots of supernatants containing equal amounts of protein were boiled in SDS-reducing buffer for $5 \mathrm{~min}$, electrophoresed on SDS-polyacrylamide gels, and transferred to nitrocellulose membranes. The membranes were blocked with $5 \%$ nonfat dry milk and probed with specific primary antibodies, followed by incubation with appropriate peroxidase-conjugated secondary antibodies. The blots were developed with ECL Plus reagent (Amersham, Arlington Heights, IL) according to the manufacturer's protocol. 


\section{Tubulin polymerization assay}

To evaluate tubulin polymerization, polymerized and non-polymerized tubulins were extracted as described elsewhere (Sackett et al., 1997). Cells were plated in six-well plates in RPMI supplemented with $10 \%$ FBS and allowed to adhere overnight. Indicated compounds were added to the medium and cells were grown for $36 \mathrm{~h}$. Cells were washed twice with PBS and lysed at $37^{\circ} \mathrm{C}$ for $5 \mathrm{~min}$ in the dark with $100 \mu \mathrm{l}$ of hypotonic buffer $(1 \mathrm{mM} \mathrm{MgCl}, 2$ mM EGTA, 0.5\% Nonidet P-40, 2 mM PMSF, 200 units $/ \mathrm{ml}$ aprotinin, $100 \mu \mathrm{g} / \mathrm{ml}$ soybean trypsin inhibitor, $5 \mathrm{mM} \varepsilon$-smino capronic acid, $1 \mathrm{mM}$ benzamidine, $20 \mathrm{mM}$ Tris- $\mathrm{Hcl}, \mathrm{pH}$ 6.8). The lysates were rinsed with $100 \mu \mathrm{l}$ of hypotonic buffer and centrifuged at $14,000 \mathrm{rpm}$ for $10 \mathrm{~min}$ at room temperature. Supernatants containing soluble (cytosolic) tubulin were separated from the pellets containing polymerized (cytoskeletal) tubulin. The pellets were resuspended in $200 \mu$ l of hypotonic buffer. Soluble and polymerized tubulins were extracted, and respective levels were assessed by immunoblotting as described above using anti- $\alpha$-tubulin antibodies.

\section{Cell cycle analysis}

After treatment, cells were harvested, washed, fixed in $80 \%$ ethanol for $30 \mathrm{~min}$, and resuspended in PBS $(\mathrm{pH} \mathrm{7.4)}$ containing $0.1 \%$ Triton $\mathrm{X}-100,5 \mu \mathrm{g} / \mathrm{ml}$ propidium iodide, and $50 \mu \mathrm{g} / \mathrm{ml}$ ribonuclease A for DNA staining. The cell-cycle distribution was analyzed using FACScan (Becton-Dickinson, San Jose, CA) and Modfit 3.0 (Verity Software, Topsham, ME) cell-cycle analysis software.

\section{Apoptosis ELISA assay}

Cytoplasmic histone-associated DNA fragments (monoand oligo nucleosomes) were quantified by a photometric enzyme immunoassay using Cell Death Detection ELISA ${ }^{\text {plus }}$ (Roche Applied Bioscience) following the manufacturer's protocol. Briefly, after treatment, cells were pooled and lysed. Cytoplasmic fractions containing histone/DNA fragments were extracted and adhered to an immobilized anti-histone antibody plate. A peroxidase-conjugated antiDNA antibody was used for detection of adhered histone/DNA fragemtns. A colorimetric substrate for peroxidase was then added to each well containing each sample. The net absorbances at the suggested wavelengths $\left(A_{405} \mathrm{~nm}\right.$ minus $\left.A_{490} \mathrm{~nm}\right)$ were obtained for the lysates derived from treated as well as control cells.

\section{Caspase activity assay}

Caspase-8- and -9-like activity was measured by cleavage of fluorogenic caspase substrates, Ac-IETD-AFC or Ac-LEHD-AFC. Briefly, $2 \times 10^{5}$ cells were seeded in 60 $\mathrm{cm}^{2}$ dishes, adhered for $24 \mathrm{~h}$. After treatment, detached and attached cells were harvested and lysed on ice in lysis buffer (50 mM Tris/ $\mathrm{HCl}(\mathrm{pH} 7.4), 1 \mathrm{mM}$ EDTA, and $10 \mathrm{mM}$ EGTA, $10 \mu \mathrm{M}$ digitonin) to generate soluble whole cell lysates. The protein concentrations in cell lysates were determined using Bio-Rad protein assay (Bio-Rad Labortories). Approximately $200 \mu \mathrm{g}$ of total protein were added to the reaction buffer (20 mM HEPES, $50 \mathrm{mM} \mathrm{NaCl}, 10 \mathrm{mM}$ dithiothreia-tocopherol, $\mathrm{pH}$ 7.5) containing Ac-IETD-AFC or Ac-LEHD-AFC $(50 \mu \mathrm{M})$. Reactions were incubated for $2 \mathrm{~h}$ at $37^{\circ} \mathrm{C}$, and the levels of released AFC was determined using the Gemini EM microplate spectroflurometer (Molecular Devices) that allowed for light excitation at $400 \mathrm{~nm}$ wavelength and emission at a wavelength of $505 \mathrm{~nm}$. The specific caspase activity, normalized for total proteins of cell lysates, was then expressed as fold of the baseline caspase activity of vehicle-treated control cells.

\section{Statistical analysis}

Statistically significant differences between values obtained under different experimental conditions were determined using two-tailed unpaired Student's $t$-tests. Synergism was assessed by the method of Chou and Talalay (1984) using a nonfixed ratio experimental design and the Calcusyn software (Biosoft, Ferguson, MO). Combination index values $<1.0$ indicates synergism.

\section{Acknowledgements}

This work was supported by the Korea Research Foundation Grant funded by the Korean Government (KRF-2006-311-E00621).

\section{References}

Alexandre J, Batteux F, Nicco C, Chereau C, Laurent A, Guillevin L, Weill B, Goldwasser F. Accumulation of hydrogen peroxide is an early and crucial step for TAX-induced cancer cell death both in vitro and in vivo. Int J Cancer 2006;119:41-8

Chou TC, Talalay P, Quantitative analysis of dose-effect relationships: the combined effects of multiple drugs or enzyme inhibitors. Adv Enzyme Regul 1984;22:27-55

Dong LF, Low P, Dyason JC, Wang XF, Prochazka L, Witting PK, Freeman R, Swettenham E, Valis K, Liu J, Zobalova R, Turanek J, Spitz DR, Domann FE, Scheffler IE, Ralph SJ, Neuzil J. $\alpha$-tocopheryl succinate induces apoptosis by targeting ubiquinone-binding sites in mitochondrial respiratory complex II. Oncogene 2008;27:4324-35

Dong LF, Freeman R, Liu J, Zobalova R, Marin-Hernandez A, Stantic M, Rohlena J, Valis K, Rodriguez-Enriquez S, Butcher B, Goodwin J, Brunk UT, Witting PK, Moreno-Sanchez R, Scheffler IE, Ralph SJ, Neuzil J. Suppression of tumor growth in vivo by the mitocan $\alpha$-tocopheryl succinate requires respiratory complex II. Clin Cancer Res 2009;15:1593-600

Ferreira CG, Span SW, Peters GJ, Kruyt FA, Giaccone G. Chemotherapy triggers apoptosis in a caspase-8-dependent and mitochondria-controlled manner in the non-small cell lung cancer cell line $\mathrm{NCl}-\mathrm{H} 460$. Cancer Res 2000; 60:7133-41

Hahn T, Szabo L, Gold M, Ramanathapuram L, Hurley LH, Akporiaye ET. Dietary administration of the proapoptotic vitamin $E$ analogue $\alpha$-tocopheryloxyacetic acid inhibits metastatic murine breast cancer. Cancer Res 2006;66: 
9374-8

Honore S, Pasquier E, Braguer D. Understanding microtubule dynamics for improved cancer therapy. Cell Mol Life Sci 2005;62:3039-56

Ihde DC, Minna JD. Non-small cell lung cancer. Part II: Treatment. Curr Probl Cancer 1991;15:105-54

Israel K, Yu W, Sanders BG, Kline K. Vitamin E succinate induces apoptosis in human prostate cancer cells: role for Fas in vitamin E succinate-triggered apoptosis. Nutr Cancer 2000;36:90-100

Kang YH, Lee E, Choi MK, Ku JL, Kim SH, Park YG, Lim SJ. Role of reactive oxygen species in the induction of apoptosis by $\alpha$-tocopheryl succinate. Int J Cancer 2004;112: 385-92

Lebedeva I, Rando R, Ojwang J, Cossum P, Stein CA. Bcl-xL in prostate cancer cells: effects of overexpression and down-regulation on chemosensitivity. Cancer Res 2000;60: 6052-60

Lee E, Choi MK, Han IO, Lim SJ. Role of p21CIP1 as a determinant of SC-560 response in human HCT116 colon carcinoma cells. Exp Mol Med 2006a;38:325-31

Lee E, Choi MK, Youk HJ, Kim CH, Han IO, Yoo BC, Lee MK, Lim SJ. 5-(4-chlorophenyl)-1-(4-methoxyphenyl)-3-trifluoromethylpyrazole acts in a reactive oxygen species-dependent manner to suppress human lung cancer growth. J Cancer Res Clin Oncol 2006b;132:223-33

Lim SJ, Lee YJ, Park DH, Lee E, Choi MK, Park W, Chun KH, Choi HG, Cho JS. $\alpha$-tocopheryl succinate sensitizes human colon cancer cells to exisulind-induced apoptosis. Apoptosis 2007;12:423-31

Neuzil J, Dong LF, Ramanathapuram L, Hahn T, Chladova M, Wang XF, Zobalova R, Prochazka L, Gold M, Freeman R, Turanek J, Akporiaye ET, Dyason JC, Ralph SJ. Vitamin E analogues as a novel group of mitocans: anti-cancer agents that act by targeting mitochondria. Mol Aspects Med 2007;28:607-45

Park SJ, Wu CH, Gordon JD, Zhong X, Emami A, Safa AR. Taxol induces caspase-10-dependent apoptosis. J Biol Chem 2004;279:51057-67

Reagan-Shaw S, Nihal M, Ahsan H, Mukhtar H, Ahmad N Combination of vitamin $\mathrm{E}$ and selenium causes an induction of apoptosis of human prostate cancer cells by enhancing Bax/Bcl-2 ratio. Prostate 2008;68:1624-34
Sackett DL, Giannakakou P, Poruchynsky M, Fojo A. Tubulin from paclitaxel-resistant cells as a probe for novel antimicrotubule agents. Cancer Chemother Pharmacol 1997; 40:228-32

Shoemaker AR, Oleksijew A, Bauch J, Belli BA, Borre T, Bruncko M, Deckwirth T, Frost DJ, Jarvis K, Joseph MK, Marsh K, McClellan W, Nellans H, Ng S, Nimmer P, O'Connor J M, Oltersdorf T, Qing W, Shen W, Stavropoulos J, Tahir SK, Wang B, Warner R, Zhang H, Fesik SW, Rosenberg SH, Elmore SW. A small-molecule inhibitor of Bcl-XL potentiates the activity of cytotoxic drugs in vitro and in vivo. Cancer Res 2006;66:8731-9

Swettenham E, Witting PK, Salvatore BA, Neuzil J. $\alpha$-tocopheryl succinate selectively induces apoptosis in neuroblastoma cells: potential therapy of malignancies of the nervous system? J Neurochem 2005;94:1448-56

Turley JM, Ruscetti FW, Kim SJ, Fu T, Gou FV, BirchenallRoberts MC. Vitamin E succinate inhibits proliferation of BT-20 human breast cancer cells: increased binding of cyclin A negatively regulates $\mathrm{E} 2 \mathrm{~F}$ transactivation activity. Cancer Res 1997;57:2668-75

von Haefen C, Wieder T, Essmann F, Schulze-Osthoff $\mathrm{K}$, Dorken B, Daniel PT. Paclitaxel-induced apoptosis in BJAB cells proceeds via a death receptor-independent, caspases-3/-8-driven mitochondrial amplification loop. Oncogene 2003;22:2236-47

Wang TH, Wang HS, Soong YK. Paclitaxel-induced cell death: where the cell cycle and apoptosis come together. Cancer 2000;88:2619-28

Weber T, Lu M, Andera L, Lahm H, Gellert N, Fariss MW, Korinek V, Sattler W, Ucker DS, Terman A, Schroder A, Erl W, Brunk UT, Coffey RJ, Weber C, Neuzil J. Vitamin E succinate is a potent novel antineoplastic agent with high selectivity and cooperativity with tumor necrosis factor-related apoptosis-inducing ligand (Apo2 ligand) in vivo. Clin Cancer Res 2002;8:863-9

Williams J, Lucas PC, Griffith KA, Choi M, Fogoros S, Hu YY, Liu JR. Expression of $\mathrm{Bcl}-\mathrm{xL}$ in ovarian carcinoma is associated with chemoresistance and recurrent disease. Gynecol Oncol 2005;96:287-95

Zanetta G, Fei F, Mangioni C. Chemotherapy with paclitaxel, ifosfamide, and cisplatin for the treatment of squamous cell cervical cancer: the experience of Monza. Semin Oncol 2000;27(1 Suppl 1):23-7 